\title{
Mineral evolution in supergene ore deposits: a key for base and critical metals deportment.
}

\author{
N. MONDILLO ${ }^{1 *}$ AND M. BONI ${ }^{1}$ \\ ${ }^{1}$ Dip. di Scienze della Terra, dell'Ambiente e delle Risorse, \\ Università degli Studi di Napoli Federico II, Napoli Italy \\ (*correspondence: nicola.mondillo@unina.it)
}

Formation of ore deposits in surficial environments is intimately associated with chemical interactions between rocks and groundwaters, whose evolution is strongly related to the climate. Several metals can be enriched in supergene ores, for example: $\mathrm{Al}, \mathrm{Ni}, \mathrm{Mn}, \mathrm{Fe}, \mathrm{Cu}, \mathrm{Zn}, \mathrm{Au}, \mathrm{U}$, etc. In this brief summary, emphasis is placed on peculiar relationships existing between mineral evolution and base and critical metals deportment in Ni-laterites, bauxites and $\mathrm{Zn}$-nonsulfide deposits.

It is well known that the combination of several factors (e.g. soil drainage, chemistry of the system, rate of weathering, parental material etc.) significantly controls the nature of Ni-ore minerals (silicates or oxides) in Ni-laterites. Among several critical metals, cobalt can be economically enriched in these ores. Differently from $\mathrm{Ni}$, its deportment is related to two main factors: the post-formation evolution of the Mn-(hydr)oxides and the petrology of the parent magmatic rock. This makes the Co exploitation in conjunction with $\mathrm{Ni}$ from Ni-laterites often challenging.

Bauxites are a common source of $\mathrm{Ga}$, and may be also considered possible future resources for REE and scandium. Gallium is incorporated into Al-hydroxides, due to the close geochemical affinity between $\mathrm{Ga}$ and $\mathrm{Al}$, and is routinely recoverd durign bauxite processing. REE and Sc accumulation in bauxites may be linked either to the presence of REE-minerals, or to REE adsorption onto Al- or Fehydroxides. Whilst REE (except $\mathrm{Ce}$ ) are preferentially enriched in Al-hydroxides, $\mathrm{Sc}$ is mostly incorporated in $\mathrm{Fe}$ hydroxides.

Sulfide deposits that are progenitors of supergene nonsulfide $\mathrm{Zn}-\mathrm{Pb}$ mineralizations contain sphalerite, which is a known host for Ge. Due to the geochemical affinity of this element to both $\mathrm{Si}$ and $\mathrm{Fe}, \mathrm{Ge}$ can be efficiently concentrated in both Zn-silicates and Fe-oxy-hydroxides in silicate-rich nonsulfide $\mathrm{Zn}$ deposits, but not in carbonate-rich ores. Interestingly, Ge enrichment seems to prevail in supergene deposits formed under tropical climates. 